\title{
Potential issues with complementary medicines commonly used in the cancer population: A retrospective review of a tertiary cancer center's experience
}

Sally L. Brooks BPharm ${ }^{1}$, Gail Rowan DipPharm BCOP ${ }^{1}$, Michael Michael MBBS (Hons), BSc (Hons), MD, FRACP ${ }^{2}$

1. Pharmacy Department, Peter MacCallum Cancer Centre, Melbourne, Australia

2. Division of Cancer Medicine, Peter MacCallum Cancer Centre, Melbourne, Australia

Running Title:Potential issues with CAM in the cancer setting

Corresponding Author: Sally Brooks - Email: Sally.Brooks@petermac.org Tel: +61385595204

Postal address! Pharmacy Department, Peter MacCallum Cancer Centre, Locked Bag 1, A’Beckett Street, Victoria, 8006, Australia

Aim: Complementary medicine (CAM) use in the cancer population is higher than the general population: some studies estimate up to $70 \%$. Our Medicines Information Centre, in a tertiary cancer institution, receives many enquiries regarding use and safety of CAM with conventional cancer therapies (chemotherapy, radiotherapy and surgery). This project aims to review the CAM most commonly enquired about with an emphasis on potential interactions with conventional cancer therapies.

Methods: An audit and review of CAM enquiries from patients or medical professionals at our centre, over a 2 An audi year period (July 2011-June 2013) was conducted. The most commonly enquired about CAM, excluding vitamins and minerals were identified, reviewed and potential interactions described.

Results: Enquiries were received from 462 patients involving 330 different CAM. The 10 CAM most commonly enquired about were fish oil (3.54\%), turmeric (3.24\%), coenzyme Q10 (2.63\%), milk thistle (2.44\%), green tea (2.38\%), ginger (2.14\%), lactobacillus (2.08\%), licorice (1.83\%), astragalus (1.77\%) and reishi mushroom (1.59\%). All were found to have predicted or potential drug interactions or therapeutic issues when combined with conventional therapies. Human studies are lacking and potential drug interactions are often predicted using in vitro or in vivo animal data.

Conclusions: Whilst many CAM may be safe when taken by themselves, there is theoretically a potential for interactions and/or increased risk of serious adverse effects when taken concurrently with conventional anticancer therapies. The paucity of human data implies their clinical significance is difficult to quantify and hence caution is required.

This is the author manuscript accepted for publication and has undergone full peer review but has not been through the copyediting, typesetting, pagination and proofreading process, which may lead to differences between this version and the Version of Record. Please cite this article as doi: 10.1111/ajco.13026.

This article is protected by copyright. All rights reserved. 


\section{Keywords}

Antineoplastic agents, complementary therapies, herb-drug interactions, neoplasms, radiotherapy

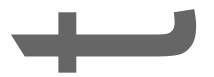

\section{Introduction}

The use of complementary medicines (CAM) in the cancer population is increasing, and is higher than in the general population. ${ }^{1}$ A 2014 single centre study at an Australian tertiary cancer institution reported the prevalence of CAM use in patients receiving chemotherapy to be $39 \% .^{2}$ A similar 2011 single centre study conducted in the UK reported the prevalence of CAM use in cancer patients to be $20-25 \% .^{3}$ A 2012 systematic review and meta-analysis of studies over the past 30 years from 18 countries $(>65,000$ cancer patients) found the prevalence of CAM use in the cancer population to be $40 \% .{ }^{4}$ The use of CAM has as expected increased with time, with an estimate of $25 \%$ in the 1970 s and 1980 s to more than $49 \%$ after $2000 .^{4}$

Many factors need to be considered when assessing the safety of ingesting a CAM in combination with standard oncological therapies such as chemotherapy and/or radiotherapy, or pre-surgery. Potential sources of adverse effects include those directly from the CAM; either fromthe agents themselves, excipients or contaminants, potential drug-drug or drug-radiation interactions, antioxidant activity, antiplatelet effects, immunomodulatory effects, estrogenic effects. These interactions can either lead to reduced therapeutic drug clearance resulting in increased toxicity or an increase in their metabolism with reduced efficacy or activation of toxic prodrugs. Similarly, they may result in greater toxicity or reduced efficacy of external beam radiotherapy or add to surgical morbidity. Hence, the effectiveness of standard cancer therapy and hence patient outcomes can be severely impacted upon in addition to the potential adverse effect of CAM alone.

CAM related enquiries form a significant portion of a Medicines Information Centre's workload. A referral

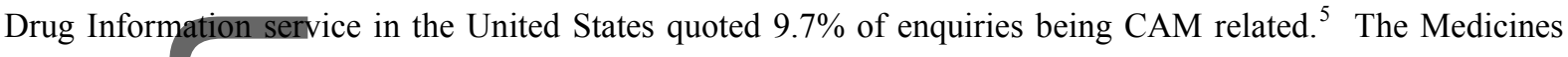
Information Centre at Peter MacCallum Cancer Centre, a tertiary oncological referral centre, receives approximately 140 enquiries per month from a range of enquirers including pharmacists, doctors, nurses and patients. A three year review (July 2012 to May 2015) of service statistics found an average of $17 \%$ (913 of 5376) of all enquiries were related to CAM and their safety in the cancer setting. Advice is ultimately given on whether it is likely safe for a patient to take a particular CAM or whether it should be avoided and if so, the reason for this and timeframe for withholding or ceasing. 
The aim of this project is to review the most commonly enquired about CAM and hence outline and discuss potential therapeutic interactions and/or issues associated with each when used in combination with conventional cancer therapies

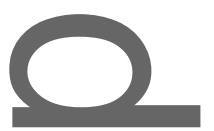

Methods

A retrospective audit and review of the CAM enquiries received by the Medicines Information Centre at Peter MacCallum Cancer Centre over a 2 year period was conducted. Records for all enquiries completed between July 2011 and June 2013 were reviewed and the following information was recorded for those relating to CAM: date of enquiry, GAM products and ingredients (product ingredients were obtained from product label or product webpage), the number of CAM products and compounds generating the enquiry and patient demographics including sex, age, cancer type, new or existing diagnosis, treatment modality and the treatment intent were obtained from the electronic medical record where the patient record number was recorded.

The ten most commonly enquired about CAM, excluding vitamins and minerals were identified and summarised. Vitamins and minerals were excluded from the study as they are often prescribed as conventional therapy and it is not always possible to separate conventional prescribing from complementary use. The potential interactions or problems associated with the use of each CAM in combination with oncological treatment (ehemotherapy and/or radiotherapy, or pre-surgery) was researched via a Medline database literature search, keywords: complementary medicine, alternative medicine, cancer, chemotherapy, radiotherapy, surgery and individual CAM name(s) and a search of two evidence based CAM databases, Natural Medicines ${ }^{6}$ and the Memorial Sloan Kettering 'About Herbs, Botanicals \& Other Products' database ${ }^{7}$.

\section{Results}

A total of 2665 enquiries were completed over the 2 year period and of these, 462 were CAM enquiries involving a total of 330 different CAM, excluding vitamins and minerals. As shown in Table 1, 42\% of enquiries involved 1 CAM product, 41\% involved 2 to 5 CAM products and 4\% involved greater than 10 products. Many of the CAM products contained combinations of multiple individual compounds with $31 \%$ of enquiries involving a single compound, 31\% involving 2 to 5 compounds, $16 \%$ involving 6 to 10 compounds and $21 \%$ involving greater than 10 compounds.

Patient demographics are shown in Table 2. Of the patients with data recorded, the majority of patients were aged over 41 and were female (62\%). Overall $57 \%$ of patients with data recorded had an existing cancer, $43 \%$ 
were newly diagnosed, $73 \%$ were being treated with adjuvant intent and $27 \%$ treated with palliative intent. The majority of enquiries received related to the use of CAM in combination with an anti-cancer agent $(56 \%)$ followed by an anti-cancer agent combined with radiotherapy (18\%).

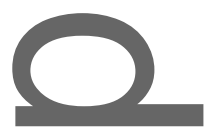

Figure 1 presents the distribution of CAM enquiries received per cancer type and shows that the most enquires are received from patients with hormone sensitive breast cancer (15\%), followed closely by haematological cancers $(14 \%)$ and gastrointestinal cancer $(11 \%)$.

The 10 most commonly enquired about CAM,excluding vitamins and minerals were fish oil (3.54\%), turmeric (3.24\%), coenzyme Q10 (2.63\%), milk thistle (2.44\%), green tea (2.38\%), ginger (2.14\%), lactobacillus $(2.08 \%)$, licorice $(1.83 \%)$, astragalus $(1.77 \%)$ and reishi mushroom $(1.59 \%)$. These low figures reflect the exceptionally high number of different CAM used in the cancer population. The summary of the literature search results for the potential interactions of these 10 most commonly enquired CAM, with standard cancer therapies is presented in Table 3. The interactions and therapeutic issues included in the review reflect those that aremost likely to have clinical significance by potentially affecting conventional cancer therapy. The recommendations relating to how these potential interactions/problems should be managed are detailed below.

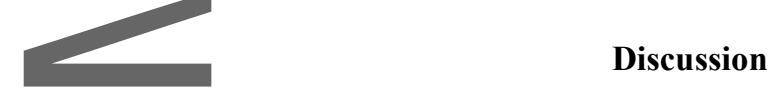

The decision on whether it is likely safe for a patient to take a particular CAM needs to be made on an individual patient basis by considering the full clinical history of the patient, the concomitant medications the patient is taking, medical comorbidities, end organ function, and the potential effects the CAM may have on their oncological disease, and its multidisciplinary treatment. The aim of this project is to review the most commonly enquired about CAM and hence outline and discuss potential therapeutic interactions and/or issues associated with each-when used in combination with conventional cancer therapies. Vitamins and minerals were from

excluded from the study as they are often prescribed as conventional therapy and it is not always possible to separate conventional prescribing from complementary use.

As summarised above, the lack of high quality data is of the greatest concern. There is a very severe paucity of high level of evidence, published in reputable sources rather than obscure journals, websites, testimonials, etc., regarding the human pharmacokinetics/pharmacodynamics of these agents, the potential and severity of the cancer therapy-CAM interactions, and the direct/indirect effects on cancer biology. Similarly the doses required 
to generate an interaction and how translatable they are from the preclinical setting to the human are also difficult to interpret. In addition to such deficiencies, there are also significant issues with the quality of the CAM preparation - the exact content of the active ingredient(s) in the various commercial preparations evaluated, the variability of the formulation itself and its impact on the bioavailability and hence systemic exposure. The commercial preparations can be manufactured from several sources across different continents with surprisingly very little or no legislative regulation controlling their manufacture at any point. In Australia, the majority of complementary medicines are listed on the Australian Register of Therapeutic Goods (ARTG) rather than registered. ${ }^{8}$ When a complementary medicine is listed on the ARTG, the therapeutic indications are not evaluated by the regulatory body, the Therapeutic Goods Administration (TGA) at the time of listing. However, at the time of listing, the sponsors are required to certify that they hold the evidence to support indications and claims made for their medicine and that this information be made available to the TGA upon request. Furthermore, there is no requirement for a complementary medicine to be listed or registered in Australia.

Hence the impact of the CAMs consumed by cancer patients need to be considered under these significant caveats. It would be ideal to recommend patients to cease all CAM whilst undertaking all active therapy for their malignancy - however the compliance of this would be extremely variable. A 2014 study by Thakerar, et al found that $2 \%$ of patients at a tertiary cancer institution chose not to follow pharmacist recommendations relating to the discontinuation of CAM due to safety issues. ${ }^{2}$

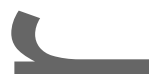

Whilst this paper focuses on the potential problems or interactions associated with CAM when used in combination with conventional cancer therapies, it is acknowledged that some CAM may have possible beneficial effects in cancer patients. ${ }^{9}$ As recommended in The Society of Integrative Oncology (SIO) guidelines for integrative oncology, our service recommends all cancer patients considering the use of CAM, have a two way conversation with a trained healthcare professional before commencing and discuss realistic expectations and potential risks and benefits. ${ }^{10}$ Realising that there will be patients who will consume CAMs despite the above, either through their own volition or advice of outside "practitioners", based on the current literature and based on the CAMs that generated enquiries through our service, general recommendations below are provided to them by our service if they wish to commence or continue with their CAM.

\section{$\underline{\text { Safety }}$}


One of the major issues with these agents is safety, which needs to be assessed from the reported literature, optimally from prospective trials or at least theoretically gleaned from known possible interactions or experimental data. For example, the consumption of green tea has been associated with several cases of hepatitis, ${ }^{11-14}$ possibly caused by active constituent, epigallocatechin-3-gallate or its metabolites, which under particular conditions related to the patient's metabolism, can induce oxidative stress in the liver ${ }^{13}$. Therefore, patients with hepatic dysfunction should consume green tea with extreme caution and monitoring of liver function tests may be warranted. In some situations, where the data suggests a CAM is potentially unsafe, patients should be advised in the strongest manner to avoid taking this CAM altogether, whether undergoing treatment for cancer or not.

\section{$\underline{\text { Interactions }}$}

There are several mechanisms by which a CAM may interact with a chemotherapy medication. Firstly, a CAM may be a substrate, inhibitor or inducer of drug metabolism or drug transport in the liver, intestine or kidney, including the cytochrome P450 (CYP) isoenzymes, uridine diphospho-glucuronosyl transferases (UGT) or membrane transporters such as $\mathrm{ABC}-\mathrm{B} 1$, also known as P-gp, etc. For example, turmeric has been shown to inhibit intestinal $\mathrm{ABC}-\mathrm{B} 1, \mathrm{CYP} 1 \mathrm{~A} 1,1 \mathrm{~A} 2$ and $3 \mathrm{~A} 4$ and induce CYP $2 \mathrm{~A} 6$ isoenzymes. ${ }^{15-21}$ Doxorubicin is a major substrate of CYP 3A4, CYP 2D6, and ABC-B1. ${ }^{22}$ The inhibitory effect of turmeric on CYP $3 \mathrm{~A} 4$ and ABC-B1 may increase serum levels of doxorubicin increasing the risk of toxicity. Another example is cyclophosphamide which is a pro-drug converted to its active form, 4-OH cyclophosphamide, via CYP 2B6, 2C9 and 3A4 isoenzymes. ${ }^{22}$ The inhibitory effect of turmeric on CYP 3A4 may reduce plasma levels of the active form of cyclophosphamide and thus decrease the anti-tumour action of cyclophosphamide.

As stated above, the doses required for these interactions to be clinically significant are poorly defined. It appears prudent that for potential interactions via this mechanism, we advise patients to avoid the CAM for at least 48 hours prior to commencement of chemotherapy until 48 hours post the completion of chemotherapy. However, 48 hours is the arbitrary pragmatic time used at our centre, though both medications and CAM have different half-lives. It would be optimally more appropriate to consider the half-life of both the medications and CAM in question and avoid the CAM for at least 5 times the longest half-life. Nevertheless, a limitation to this method is the severe paucity of data regarding CAM pharmacokinetics. 
Secondly, at the level of drug absorption interactions can also occur. For example, intravenous administration of licorice can uncommonly cause diarrhoea ${ }^{6}$ and thus may theoretically reduce the absorption of other oral medications when taken concurrently. ${ }^{6}$ In this situation, it is advised that the administration of oral medications occurs at least an hour before, or two hours after the administration of CAM that may interfere with drug absorption.

$$
\text { . }
$$

Interactions via othen mechanisms are also possible. Fish oil has been shown to contain substantial levels of platinum-induced fatty acid (PIFA) 16:4(n-3), which has been shown to induce resistance to chemotherapy in preclinical mouse models. ${ }^{23} \mathrm{~A}$ recent preclinical study in mice found that fish oil increased tumour volume by an estimated $142.4 \mathrm{~mm}^{3}, 166.3 \mathrm{~mm}^{3}$ and $147.1 \mathrm{~mm}^{3}$ for cisplatin, irinotecan and oxaliplatin, respectively. Based on these-findings, the investigators advise fish oil is avoided from the day prior to commencement of chemotherapy until the day after completion of chemotherapy. ${ }^{23}$

Preliminary in vitro and in vivo data shows that green tea polyphenols are antagonist with bortezomib and other boronic acid-based proteasome inhibitors. The former blocks the proteasome inhibitory effects of the latter, leading to reduced cell apoptosis. ${ }^{24}$ The concentrations of the most active constituent of green tea, epigallocatechin gallate (EGCG) studied are consistent with those achieved in the blood of humans ingesting green tea. ${ }^{24}$ Therefore, green tea should be avoided by patients being treated with bortezomib.

\section{$\underline{\text { Antioxidants }}$}

Some CAM such as milk thistle and green tea possess antioxidant activity. ${ }^{25-27}$ The use of antioxidants in combination with radiotherapy and chemotherapy agents that generate free radicals remains controversial. ${ }^{28}$ Some data suggest antioxidants may reduce treatment-related adverse effects of radiotherapy and chemotherapy and other data suggest antioxidants protect both tumour cells and healthy cells from oxidative damage generated by radiation therapy and some chemotherapy agents, and thus may possibly result in tumour protection. ${ }^{28}$ Chemotherapy agents that generate free radicals include the alkylating and alkylating-like agents,eg. cisplatin, carboplatin, ehlorambucil, carmustine, cyclophosphamide, busulfan, ifosfamide, anthracyclines,eg. doxorubicin, daunorubicin, epirubicin, and podophyllotoxin agents, eg. etoposide and teniposide. Our general advice regarding CAM with antioxidant activity is to avoid them for at least 48 hours pre chemotherapy agents that generate free radicals and radiotherapy, until 48 hours post treatment. Nevertheless, as stated above a limitation to this recommendation is the severe paucity of data regarding CAM pharmacokinetics, 
and similarly mechanistic studies assessing the time profile of the interaction between antioxidants and treatment-induced radicals.

\section{$\underline{\text { Antiplatelet effects }}$}

CAM with antiplatelet effects including ginger, turmeric and high doses of fish oil and reishi mushroom may increase the risk of bleeding in patients who are thrombocytopenic, undergoing surgery, or taking concomitant anticoagulants. ${ }^{29-37}$ Consider turmeric, in which the major active constituents are curcuminoids, mainly curcumin. ${ }^{6}$ Preliminary research suggests curcumin might inhibit platelet-activating factor and arachidonic acid platelet aggregation, possibly interfering with thromboxane synthesis and thus decreasing platelet aggregation. ${ }^{29}$, ${ }^{30}$ It is often difficutt to establish the clinical significance of these effects in the haematology/oncology setting due to the lack of human data.

The effect of some CAM on platelet aggregation is unclear. For example, in healthy humans, a reishi mushroom dose of $3 \mathrm{~g}$ per day has been shown to reduce platelet aggregation, ${ }^{37}$ however a dose of $1.5 \mathrm{~g}$ daily did not affect platelet aggregation ${ }^{33}$ therefore there may be a dose relationship. We advise that CAM with anticoagulant properties are ceased 2 weeks prior to surgery and are avoided in patients who are thrombocytopenic or bleeding. They should be used with extreme caution in patients taking concomitant anticoagulants.

\section{Immunomodulatory effects}

Some CAM have immunostimulatory or immunosuppressive effects and thus may interfere with the efficacy and/or toxicity of immunosuppressive therapy such as chemotherapy and immunotherapy agents such as ipilimumab and immune checkpoint inhibitors such as PD1 antagonists. Astragalus has demonstrated immunostimulatory effects in in vitro and in vivo. ${ }^{38-40}$ In mice, the polysaccharide constituents of astragalus appear to bind and activate $\mathrm{B}$ cells and macrophages. ${ }^{39}$ Other in vitro and in vivo research has found that astragalus may increase the activity, and/or number of T cells. ${ }^{38,40}$

We advise that CAM with immunomodulatory properties are avoided for 48 hours pre and post immunosuppressive agents such as chemotherapy and are avoided altogether by patients being treated with immunotherapy agents.

\section{Estrogenic effects}


There are CAM including turmeric, milk thistle, licorice and astragalus are thought to have estrogenic effects ${ }^{41-}$

${ }^{50}$ and should be avoided altogether by patients with hormone sensitive cancers and conditions such as breast cancer, ovarian cancer and endometriosis. Animal data suggest silymarin, a constituent of milk thistle can bind to estrogen receptors and therefore may theoretically have estrogenic effects. ${ }^{46}$

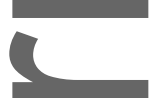

Preliminary data suggest estrogenic activity may sometimes be concentration dependent as with the major constituent of licorice, glabridin, which appears to have an estrogen receptor-dependent, growth-promoting effect at low concentrations and estrogen receptor-independent antiproliferative activity at higher concentrations. ${ }^{41}$ Furthermore, due to lack of data, the extent of estrogenic activity and the mechanism for such activity is often unknown making it difficult to establish the clinical significance of potential effects.

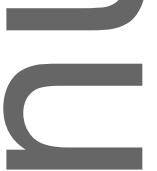

\section{Conclusion}

Cancer patients do consider the use or actually consume CAM during their cancer therapy. Whilst many CAM may be considered "safe" when taken by themselves, even with lack of high level data, there is theoretically, a potential for interactions (at PK/PD level) or an increased risk of serious adverse effects when taken concurrently with conventional anticancer therapies such as chemotherapy and/or radiotherapy, or when taken pre-surgery. The end result may be either increased toxicity from the cancer therapy, or on the other hand reduced treatment efficacy. These aspects have been highlighted by the review of CAM enquiries made to a tertiary cancer centre Medicine Information Service over a 2 year period and a literature review of the 10 most frequent CAM that generated the enquiry. Human studies and high level evidence are both severely lacking in this area and potential drug interactions often need to be implied/predicted using in vitro data or in vivo animal data, making it difficult to quantify the clinical significance. Similarly the quality control of the CAM preparations is also suspect and unregulated in most circumstances. It would be thus ideal to recommend patients to cease all CAMs whilst undertaking all active therapy for their malignancy - however the compliance of this would be extremely variable. Realising that there will be patients that will consume CAMs despite the above, generatadvice can be provided to them if they wish to commence or continue with their CAM.

\section{Conflict of Interest}

The authors declare that there is no conflict of interest.

\section{References}


1. Anderson JG and Taylor AG. Use of complementary therapies for cancer symptom management: results of the 2007 National Health Interview Survey. Journal of alternative and complementary medicine (New York, NY). 2012; 18: 235-41.

2. Thakerar A, Sanders J, Moloney M, Alexander M and Kirsa S. Pharmacist advice on the safety of Complementary and Alternative Medicines during conventional anticancer treatment. J Pharm Pract Res. 2014; 44: 231-7.

3. Damery $S$, Gratus $C$, Grieve R, et al. The use of herbal medicines by people with cancer: a cross-sectional survey. Br J Cancer. 2011; 104: 927-33.

4. Horneber M, Bueschel G, Dennert G, Less D, Ritter E and Zwahlen M. How many cancer patients use complementary and alternative medicine: a systematic review and metaanalysis. Integrative cancer therapies. 2012; 11: 187-203.

5. Gregory PJ, Jalloh MA, Abe AM, Hu J and Hein DJ. Characterization of Complementary and Alternative Medicine-Related Consultations in an Academic Drug Information Service. J Pharm Pract. 2015.

6. Natural Medicines Comprehensive Database. Stockton, CA.

7. About Herbs, Botanicals \& Other Products. Memorial Sloan-Kettering Cancer Centre (MSKCC). New York, USA.

8. Australian Government DoH, Therapeutic Goods Adminstration. An overview of the regulation of complementary medicines in Australia. 2013.

9. Frenkel M, Abrams DI, Ladas EJ, et al. Integrating Dietary Supplements Into Cancer Care. Integrative cancer therapies. 2013; 12: 369-84.

10. Deng GE, Frenkel M, Cohen L, et al. Evidence-based clinical practice guidelines for integrative oncology: complementary therapies and botanicals. Journal of the Society for Integrative Oncology. 2009; 7: 85-120

11. Vanstraelen S, Rahier J and Geubel AP. Jaundice as a misadventure of a green tea (camellia sinensis) lover : a case report. Acta gastro-enterologica Belgica. 2008; 71: 409-12.

12. Verhelst $X$, Burvenich P, Van Sassenbroeck D, Gabriel C, Lootens M and Baert D. Acute hepatitis after treatment for hair loss with oral green tea extracts (Camellia Sinensis). Acta gastroenterologica Belgica. 2009; 72: 262-4.

13. Mazzanti G, Menniti-Ippolito F, Moro PA, et al. Hepatotoxicity from green tea: a review of the literature and two unpublished cases. European journal of clinical pharmacology. 2009; 65: 33141.

14. Fernandez J, Navascues C, Albines G, Franco L, Pipa M and Rodriguez M. Three cases of liver toxicity with a dietary supplement intended to stop hair loss. Revista espanola de enfermedades digestivas : organo oficial de la Sociedad Espanola de Patologia Digestiva. 2014; 106: 552-5.

15. Ampasavate $\mathrm{C}$, Sotanaphun $\mathrm{U}$, Phattanawasin P and Piyapolrungroj N. Effects of Curcuma spp. on P-glyeoprotein function. Phytomedicine. 2010; 17: 506-12.

16. Zhang W, Tan T and Lim L. Impact of curcumin-induced changes in P-glycoprotein and CYP3A expression on the pharmacokinetics of peroral celiprolol and midazolam in rats. Drug Metab Dispos. 2007; 35:110-5.

17. Zhou S, Lim LY and Chowbay B. Herbal modulation of P-glycoprotein. Drug metabolism reviews. 2004; 36: 57-104.

18. Cialino H, Daschner P, Wang T and Yeh G. Effect of curcumin on the aryl hydrocarbon receptor and cytochrome P450 1A1 in MCF-7 human breast carcinoma cells. Biochem Pharmacol. 1998; 56:197-206.

19. Chen Y, Liu W, Chen B, Fan L, Han Y and Wang G. Plant polyphenol curcumin significantly affects CYP1A2 and CYP2A6 activity in healthy, male Chinese volunteers. Ann Pharmacother. 2010; 44: 1038-45.

20. Appiah-Opong R, Commandeur JN, van Vugt-Lussenburg B and Vermeulen NP. Inhibition of human recombinant cytochrome $\mathrm{P} 450$ s by curcumin and curcumin decomposition products.

Toxicology. 2007; 235: 83-91.

This article is protected by copyright. All rights reserved. 
21. Hou XL, Takahashi K, Kinoshita N, et al. Possible inhibitory mechanism of Curcuma drugs on CYP3A4 in 1alpha, 25 dihydroxyvitamin D3 treated Caco-2 cells. International journal of pharmaceutics. 2007; 337: 169-77.

22. Micromedex 2.0 DRUGDEX ${ }^{\circledR}$. Thomson Reuters, 2017.

23. Daenen LM, Cirkel GA, Houthuijzen JM and et al. Increased plasma levels of chemoresistance-inducing fatty acid 16:4(n-3) after consumption of fish and fish oil. JAMA Oncol. 2015; 1 : 350-8

24. Golden EB, Lam PY, Kardosh A, et al. Green tea polyphenols block the anticancer effects of bortezomib and other boronic acid-based proteasome inhibitors. Blood. 2009; 113: 5927-37.

25. Carini R, Comoglio A, Albano E and Poli G. Lipid peroxidation and irreversible damage in the rat hepatocyte model. Protection by the silybin-phospholipid complex IdB 1016. Biochem Pharmacol. 1992; 43: 2111-5.

26. Basaga H, Poli G, Tekkaya $\mathrm{C}$ and Aras I. Free radical scavenging and antioxidative properties of 'silibin' complexes on microsomal lipid peroxidation. Cell Biochem Funct. 1997; 15: 27-33.

27. Forester SC and Lambert JD. The role of antioxidant versus pro-oxidant effects of green tea polyphenols in cancer prevention. Molecular nutrition \& food research. 2011; 55: 844-54.

28. Lawenda BD, Kelly KM, Ladas EJ, Sagar SM, Vickers A and Blumberg JB. Should Supplemental Antioxidant Administration Be Avoided During Chemotherapy and Radiation Therapy? . Journal of the National Cancer Institute. 2008; 100: 773-83.

29. Shah B, Nawaz Z, Pertani S, et al. Inhibitory effect of curcumin, a food spice from turmeric, on platelet-activating factor- and arachidonic acid-mediated platelet aggregation through inhibition of thromboxane formation and Ca2+ signaling. Biochem Pharmacol. 1999; 58: 1167-72.

30. Prakash P, Misra A, Surin W, et al. Anti-platelet effects of Curcuma oil in experimental models of myocardial ischemia-reperfusion and thrombosis. Thromb Res. 2011; 127: 111-8.

31. Srivastava KC. Aqueous extracts of onion, garlic and ginger inhibit platelet aggregation and alter arachidonic acid metabolism. Biomedica biochimica acta. 1984; 43: S335-46.

32. Thomson M, Al-Qattan KK, Al-Sawan SM, Alnaqeeb MA, Khan I and Ali M. The use of ginger (Zingiber officinale Rosc.) as a potential anti-inflammatory and antithrombotic agent. Prostaglandins, leukotrienes, and essential fatty acids. 2002; 67: 475-8.

33. Kwok Y, Ng KF, Li CC, Lam CC and Man RY. A prospective, randomized, double-blind, placebocontrolled study of the platelet and global hemostatic effects of Ganoderma lucidum (Ling-Zhi) in healthy volunteers. Anesthesia and analgesia. 2005; 101: 423-6.

34. Goodnight SH, Jr., Harris WS and Connor WE. The effects of dietary omega 3 fatty acids on platelet composition and function in man: a prospective, controlled study. Blood. 1981; 58: 880-5. 35. Zucker ML, Bilyeu DS, Helmkamp GM, Harris WS and Dujovne CA. Effects of dietary fish oil on platelet function and plasma lipids in hyperlipoproteinemic and normal subjects. Atherosclerosis. 1988; 73: $13-22$.

36. Gajos G, Rostoff P, Undas A and Piwowarska W. Effects of polyunsaturated omega-3 fatty acids on responsiveness to dual antiplatelet therapy in patients undergoing percutaneous coronary intervention: the OMEGA-PCI (OMEGA-3 fatty acids after pci to modify responsiveness to dual antiplatelet therapy) study. J Am Coll Cardiol. 2010; 55: 1671-8.

37. Tao J and Feng KY. Experimental and clinical studies on inhibitory effect of ganoderma lucidum on platelet aggregation. Journal of Tongji Medical University = Tong ji yi ke da xue xue bao. 1990; 10: 240-3.

38. Cai XY, XU YL and Lin XJ. [Effects of radix Astragali injection on apoptosis of lymphocytes and immune function in patients with systemic lupus erythematosus]. Zhongguo Zhong xi yi jie he za zhi Zhongguo Zhongxiyi jiehe zazhi = Chinese journal of integrated traditional and Western medicine. 2006; 26: 443-5.

39. Shao BM, Xu W, Dai H, Tu P, Li Z and Gao XM. A study on the immune receptors for polysaccharides from the roots of Astragalus membranaceus, a Chinese medicinal herb. Biochemical and biophysical research communications. 2004; 320: 1103-11. 
40. Chu DT, Wong WL and Mavligit GM. Immunotherapy with Chinese medicinal herbs. I.

Immune restoration of local xenogeneic graft-versus-host reaction in cancer patients by fractionated Astragalus membranaceus in vitro. Journal of clinical \& laboratory immunology. 1988; 25: 119-23.

41. Tamir S, Eizenberg M, Somjen D, et al. Estrogenic and antiproliferative properties of glabridin from licorice in human breast cancer cells. Cancer Res. 2000; 60: 5704-9.

42. Bachmeier $B$, Mirisola V, Romeo F, et al. Reference profile correlation reveals estrogen-like trancriptional activity of Curcumin. Cell Physiol Biochem. 2010; 26: 471-82.

43. Kim I, Kang S, Kim K, Choung E and Zee O. Screening of estrogenic and antiestrogenic activities from medicinal plants. Environ Toxicol Pharmacol. 2008; 25: 75-82.

44. Singh $\mathrm{M}$ and Singh N. Curcumin counteracts the proliferative effect of estradiol and induces apoptosis in cervical cancer cells. Mol Cell Biochem. 2011; 247: 1-11.

45. Calaf G, Echiburú-Chau C, Wen G, Balajee A and Roy D. Effect of curcumin on irradiated and estrogen-transformed human breast cell lines. Int J Oncol. 2012; 40: 436-42.

46. El-Shitany NA, Hegazy S and El-Desoky K. Evidences for antiosteoporotic and selective estrogen receptor modulator activity of silymarin compared with ethinylestradiol in ovariectomized rats. Phytomedicine. 2010; 17: 116-25.

47. Somjen D, Knoll E, Vaya J, Stern $\mathrm{N}$ and Tamir S. Estrogen-like activity of licorice root constituents: glabridin and glabrene, in vascular tissues in vitro and in vivo. The Journal of steroid biochemistry and molecular biology. 2004; 91: 147-55.

48. Simons R, Vincken J-P, Mol LAM, et al. Agonistic and antagonistic estrogens in licorice root (Glycyrrhiza glabra). Anal Bioanal Chem. 2011; 401: 305-13.

49. Zhang $\mathrm{CZ}$, Wang SX, Zhang Y, Chen JP and Liang XM. In vitro estrogenic activities of Chinese medicinal plants traditionally used for the management of menopausal symptoms. Journal of ethnopharmacology. 2005; 98: 295-300.

50. Chen J, Zhang $X$, Wang $Y, Y e Y$ and Huang Z. Formononetin promotes proliferation that involves a feedback loop of microRNA-375 and estrogen receptor alpha in estrogen receptor-positive cells. Molecular carcinogenesis. 2016; 55: 312-9.

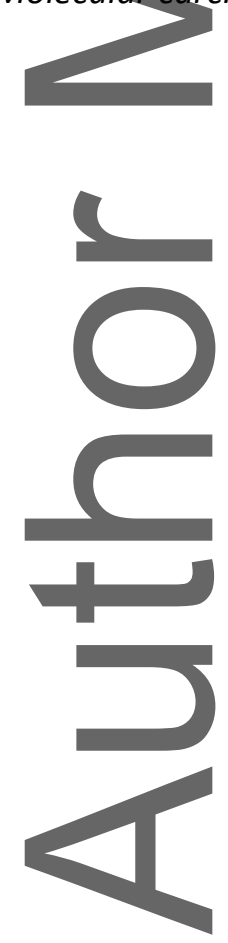

This article is protected by copyright. All rights reserved. 
Table 1. Number of CAM products and compounds per enquiry

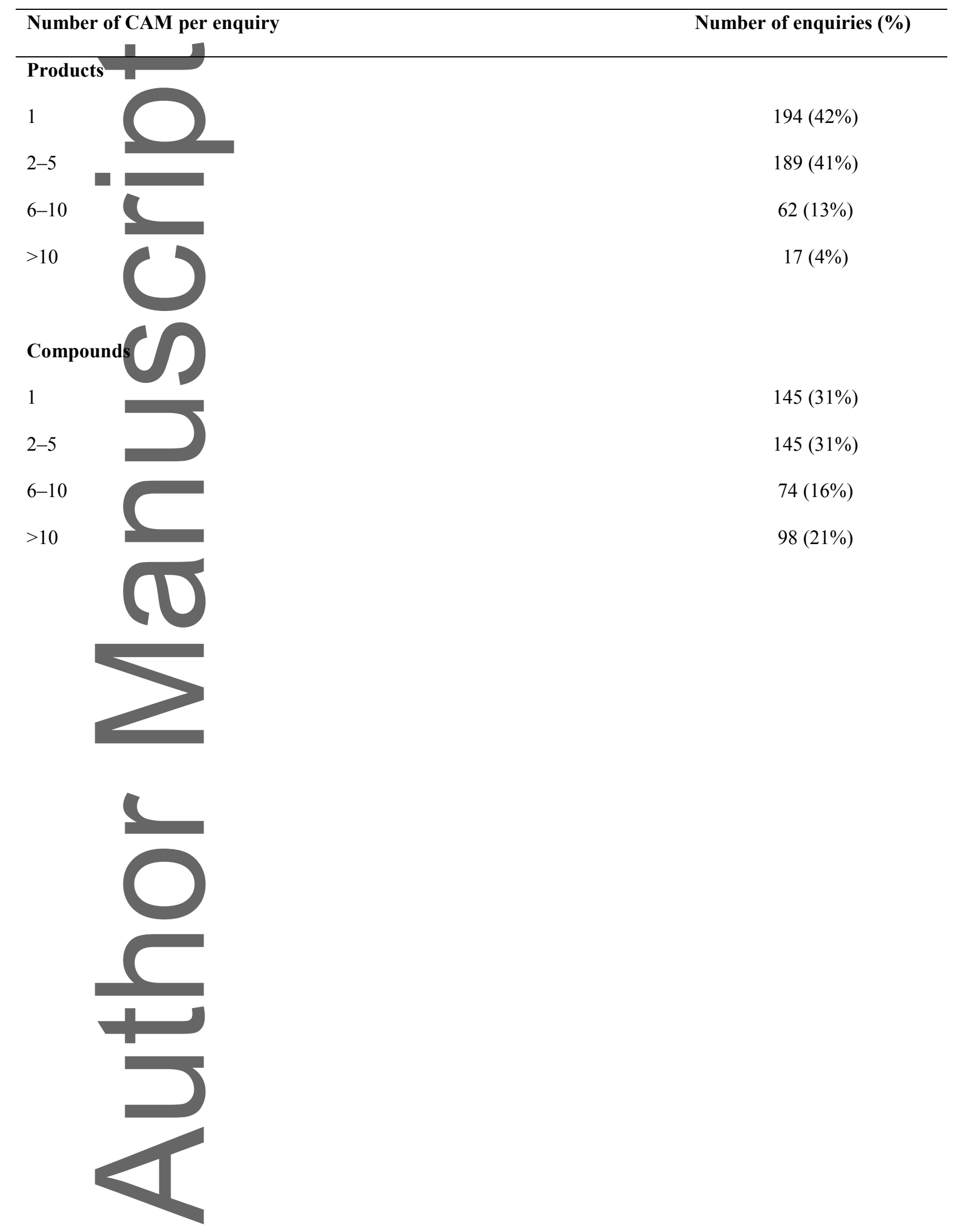

This article is protected by copyright. All rights reserved. 


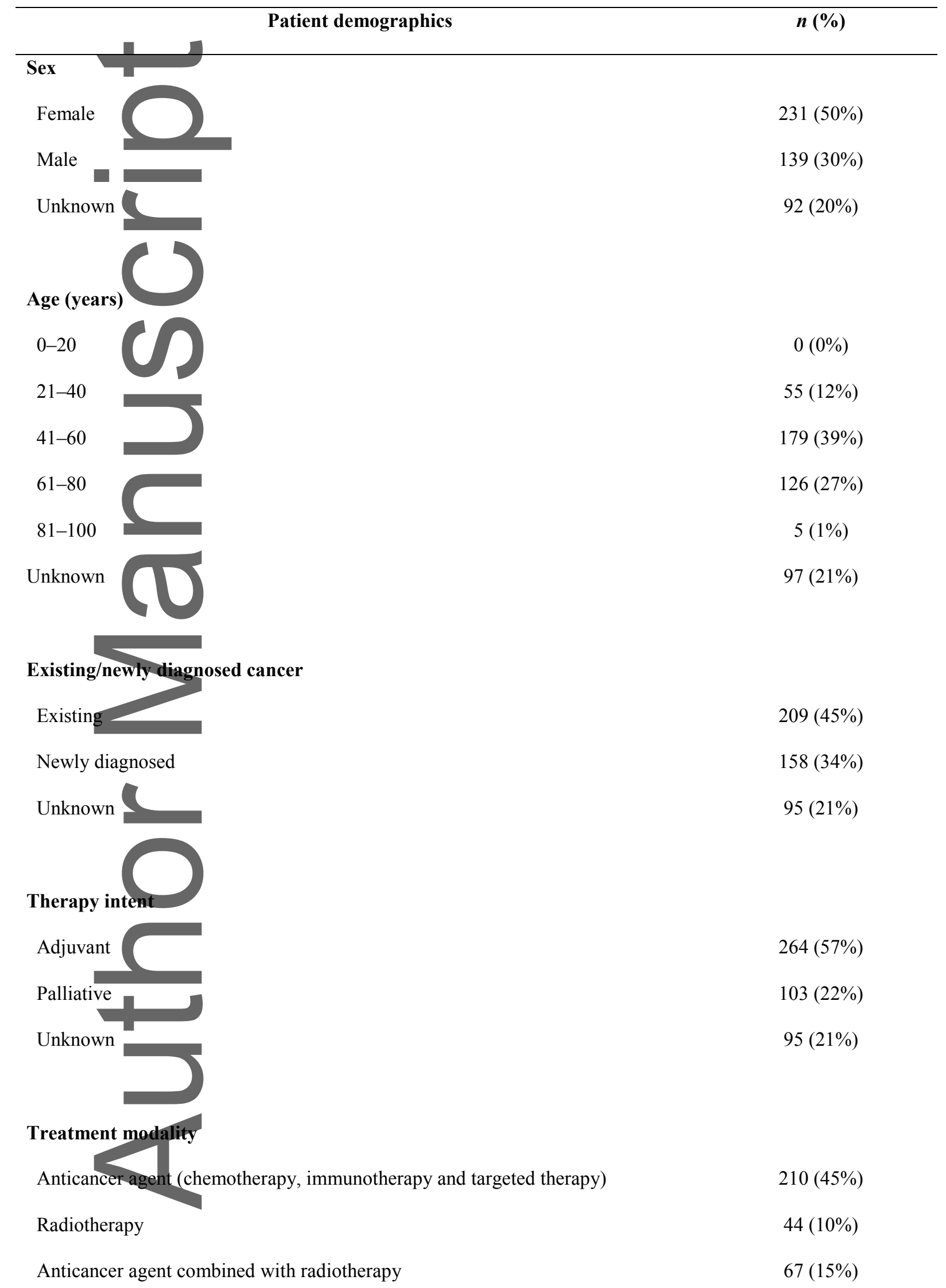


Anticancer agent combined with surgery

Other

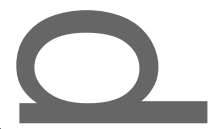

Unknown

$10(2 \%)$

$86(19 \%)$
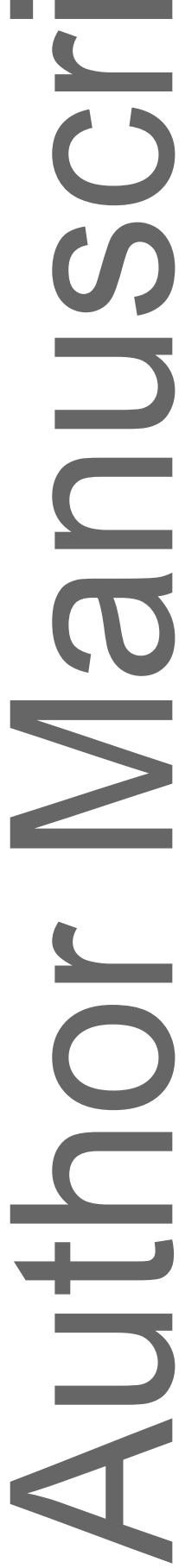
Table 3. Summary of interactions/problems associated with the top 10 CAMs

\begin{tabular}{|c|c|c|c|c|}
\hline CAM & Drug interactions & $\begin{array}{l}\text { Antioxidant } \\
\text { activity }\end{array}$ & $\begin{array}{l}\text { Antiplatelet } \\
\text { activity }\end{array}$ & Other \\
\hline Fish oil & $\begin{array}{l}\text { May decrease activity of } \\
\text { chemotherapy } \dagger\end{array}$ & Nil & $\begin{array}{l}\text { At doses }>3 \\
g / \text { day } \dagger\end{array}$ & $\begin{array}{l}\text { Possible immunostimulatory } \\
\text { effects at doses }>3 \mathrm{~g} / \text { day } \dagger\end{array}$ \\
\hline Turmeric $\square$ & $\begin{array}{l}\text { Inhibits P-gp †t } \\
\text { Inhibits CYP 1A1†t } \\
\text { Inhibits CYP 1A2†t }\end{array}$ & Yes†t & Yestit & $\begin{array}{l}\text { Possible immunostimulatory } \\
\text { effects } \dagger \\
\text { ?Estrogenic effects } \dagger \\
\text { ?Antiestrogenic effects } \dot{\dagger}\end{array}$ \\
\hline Coenzyme $Q$ & Nil & Yes $\dagger$ & Nil & $\begin{array}{l}\text { Possible immunostimulatory } \\
\text { effects } \dagger\end{array}$ \\
\hline Milk thistle & $\begin{array}{l}\text { Inhibits UGT } \ddagger \\
\text { Inhibits P-gp } \dagger\end{array}$ & Yestt & Nil & Estrogenic effects $\dagger$ \\
\hline Green tea & $\begin{array}{l}\text { Inhibits UGT†t } \\
\text { Inhibits OATP } 1 \mathrm{~A} 2 \uparrow t \\
\text { Inhibits OATP } 1 \mathrm{~B} 1 \uparrow t \\
\text { Inhibits OATP } 2 \mathrm{~B} 1 \uparrow t\end{array}$ & Yes†t & $\begin{array}{l}\text { Not reported in } \\
\text { humanst }\end{array}$ & $\begin{array}{l}\text { Inhibits therapeutic effect of } \\
\text { bortezomib†t } \\
\text { Linked to several cases of } \\
\text { hepatotoxicity† }\end{array}$ \\
\hline Ginger & Increases tacrolimus levels & Yestt & Yestt & Nil \\
\hline Lactobaciltu & Nil & Nil & Nil & $\begin{array}{l}\text { Risk of pathogenic colonization } \\
\text { in immunocompromised patients† }\end{array}$ \\
\hline Licorice & $\begin{array}{l}\text { Intribits P-gp: } \\
\text { Inhhibits CYP 2B6‡ } \\
\text { Inhibits CYP } 2 \mathrm{C} 9 \ddagger \\
\text { ?nduces CYP } 2 \mathrm{C} 9 \dagger \\
\text { ?nduces CYP } 3 \mathrm{~A} 4 \dagger\end{array}$ & Yestt & Nil & $\begin{array}{l}\text { ?Estrogenic effects } \uparrow \dagger \\
\text { ?Antiestrogenic effects } \dagger \dagger\end{array}$ \\
\hline
\end{tabular}

This article is protected by copyright. All rights reserved. 


\begin{tabular}{|l|l|l|l|l|}
\hline & ?Reduces effects of cisplatin $\dagger$ & & & \\
\hline Astragalus & Nil & Yes $\ddagger$ & Nil & Immunostimulatory effects $\dagger$ \\
\hline Reishi mushroom & Inhibits CYP 1A2 $\dagger$ & Yes $\ddagger$ & High doses $\dagger$ & $\begin{array}{l}\text { Possible immunostimulatory } \\
\text { effects } \dagger\end{array}$ \\
& Inhibits CYP 2E1 $\dagger$ & & $\begin{array}{l}\text { Possible immunosuppressive } \\
\text { effects } \ddagger\end{array}$ \\
\hline
\end{tabular}

$\dagger$ In vivo (animal/human).

CYP, cytochrome P450: P-gp, P-glycoprotein (also known as ABC-B1); UGT, uridine 5-diphospho-glucuronosyltransferase; OATP, organic anion-transporting polypetide.

Note: Fully referenced copy of Table 3 is available as Supplementary Document 1.

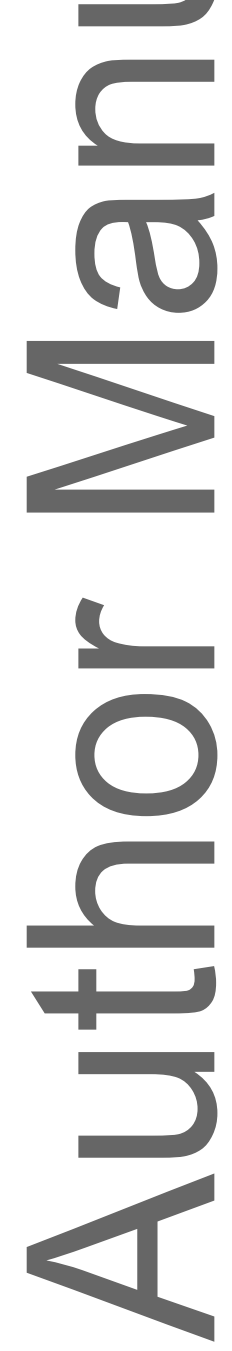


Figure 1. CAM enquiries per cancer type.

Figure 1. CAM enquiries per cancer type
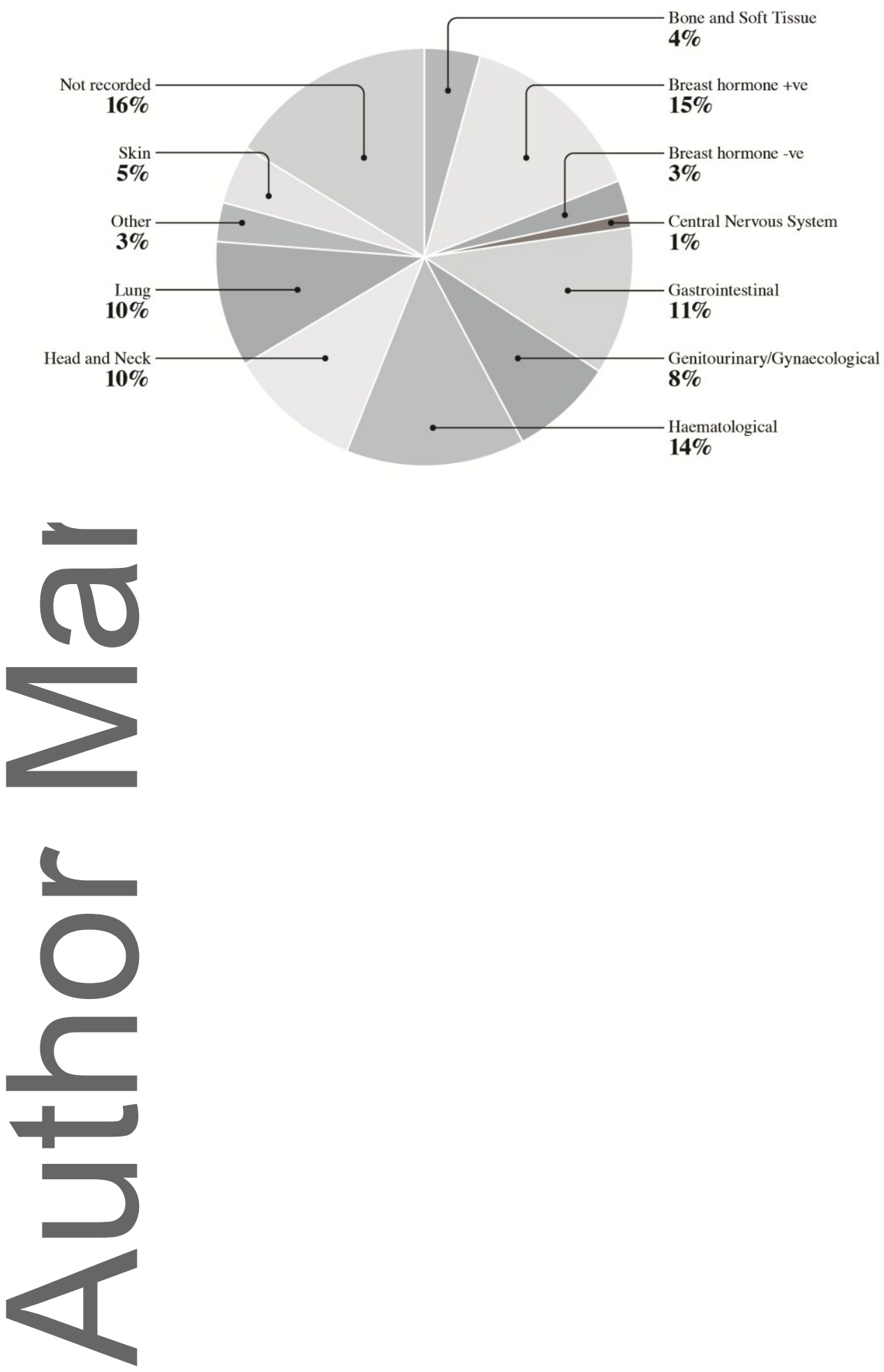

This article is protected by copyright. All rights reserved. 


\section{University Library}

\section{- M M I E E R VA A gateway to Melbourne's research publications}

Minerva Access is the Institutional Repository of The University of Melbourne

Author/s:

Brooks, SL;Rowan, G;Michael, M

Title:

Potential issues with complementary medicines commonly used in the cancer population: A retrospective review of a tertiary cancer center's experience

Date:

2018-10-01

Citation:

Brooks, S. L., Rowan, G. \& Michael, M. (2018). Potential issues with complementary medicines commonly used in the cancer population: A retrospective review of a tertiary cancer center's experience. ASIA-PACIFIC JOURNAL OF CLINICAL ONCOLOGY, 14 (5), pp.e535-e542. https://doi.org/10.1111/ajco.13026.

Persistent Link:

http://hdl.handle.net/11343/284238 